\title{
The Proximity Effect
}

\author{
Elton N. Kaufmann, MRS President
}

During a break in the proceedings of a meeting at the National Academy of Sciences last month, I found myself, coffee cup in hand, standing outside the Constitution Avenue entrance gazing at the pensive bronze image of Albert Einstein as it was pondered by a few tourists. While wondering where those visitors placed so great a scientific mind in their own personal scheme of things and feeling somewhat inspired myself, I was joined by David Nagel of the Naval Research Laboratory. We got to talking about the tourism phenomenon per se and wondered whether many Washington, DC area residents had stopped to examine the Einstein likeness. We agreed (without knowledge of any properly conducted survey) that people tend to visit all the interesting sites while traveling but are much less likely to include such a visit on their daily schedule in their local area.

One can hypothesize why. The local always appears less exotic than the distant (a variant on "the grass is greener" syndrome). Or, perhaps one always imagines that there will be many other more convenient times than now to make the explicit effort to visit something so readily at hand. No matter. As I began to perceive that an analogous behavior applies to conference attendees, Dr. Nagel advised me that the phenomenon over which we were musing was called the "proximity effect."

Proximity, indeed. The phenomenon that I was trying to enunciate was just that. I have often found myself in intense technical discussions with colleagues from my own institution while attending a conference. Sometimes with coworkers whose labs or offices were only a few steps from mine. Why did it seem more natural to have these

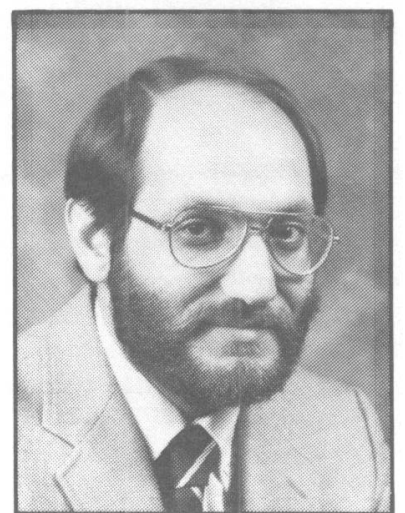

discussions while away from home. In this way, I frequently learned of interesting and potentially useful goings-on that I later followed up on my return. It would seem a rather round about way to maximize one's coupling to one's own institution.

Another side of this phenomenon is the chagrin one experiences when a colleague from a distant institution tells you of work carried out by your coworkers of which you were unaware

Before carrying this to an extreme, however, let's acknowledge that we all try to keep abreast of activities at home and that our institutions often provide a variety of tools, such as seminars and internal publications, to help us. But it seems that because they are so readily available, and because we are all so busy with many pressing duties of the day, the proximity effect inhibits us.

When attending a conference, our focus is narrower, extraneous interruptions are fewer, and the atmosphere seems more conducive to these types of exchanges. Bumping in to a coworker while conferen- cing is just an accidental use of the sequestered-retreat method frequently employed by committees and task forces.

What should one do about the proximity effect? I see two alternatives. If you are a resident of the Washington, $\mathrm{DC}$ area, visit the local sites as if your were from Spokane and don't forget the likeness of Einstein. And, if you realize that proximity is affecting your interaction with your coworkers, make a concerted effort to walk through the halls of your laboratory asking people about the exciting things with which they're involved. On the other hand, since the proximity effect is a staple of human nature we could turn it to our advantage. To appreciate local attractions, research your area and play tour guide for relatives from out of town. And as materials research scientists, put conferences on your calendars where you are likely to have the most fruitful interactions. May we suggest that the Fall Meeting of the MRS in Boston this year is an eminent candidate for taking full advantage of the ubiquitous proximity effect.

\section{Plan Now To Take Advantage of JOB PLACEMENT CENTER In Conjunction with 1985 MRS Fall Meeting}

The Job Placement Center, to be held in conjunction with the 1985 MRS Fall Meeting in Boston (December 2-6), is a valuable way to become acquainted with important contacts in materials research and make your credentials known to them. See the Job Placement Form in this issue. Fee: $\$ 5.00^{*}$ (Make checks payable to American Institute of Physics).

\author{
A confidential service of the American Institute of Physics \\ on behalf of the Materials Research Society.
}




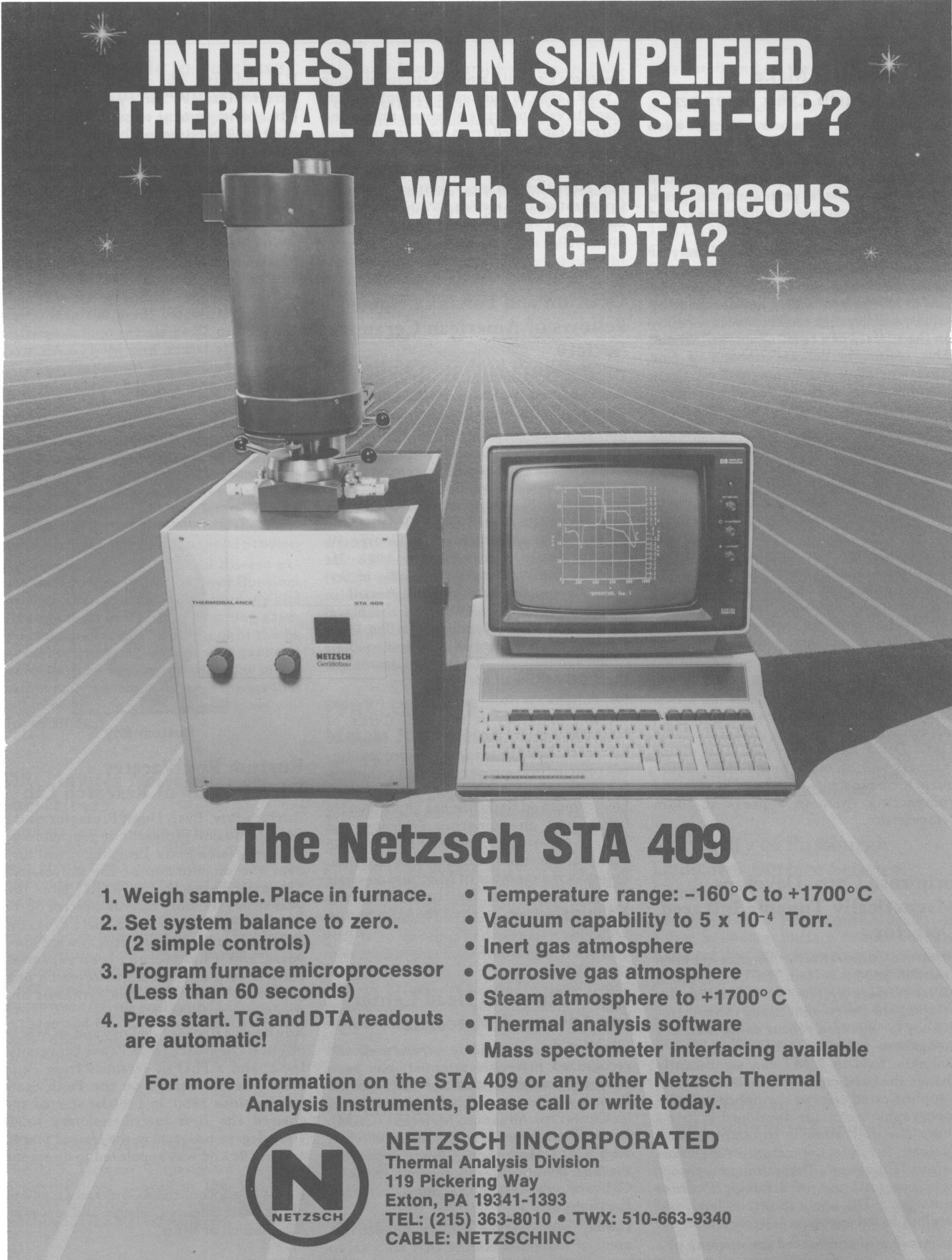

